\title{
/COMMENTARY
}

\section{The Strange Case of the Pitter}

\section{7}

he pitter" was the colloquial name given to a strange bacterium I first heard about during my undergraduate days over 30 years ago. The pitter had been studied in the department from time to time without anyone learning very much about it. Rumored to be called Eikenella (no one was really sure), the organism was characterized by the deep pits it created when cultured on blood agar. This was virtually the only medium on which it would grow at alland then exceedingly slowly. Every so often, a hapless undergraduate would be handed the bacterium as the subject for a final-year project. Invariably, the fastidious beast died out a week or two later. End of project.

I could not have guessed what a high-profile career lay ahead for Eikenella corrodens. In the 1970s, it was recognized as an opportunistic pathogen in drug abusers and postoperative patients. During the $1980 \mathrm{~s}$, it emerged as one of the most frequent causes of infection on those fractious occasions when human bites human. Now, in the $1990 \mathrm{~s}, E$. corrodens has become the subject of some sophisticated molecular biology designed to identify the genes that give this singular organism the capacity to invade and destroy human tissues. Down at the University of Florida in Gainesville, Ann Progulske-Fox and her colleagues announced recently that they have cloned and sequenced at least two of those genes for the first time.

A bacillus of modest proportions, E. corrodens does indeed proliferate painfully slowly. It requires hemin, and after several days of unimpressive growth on blood-containing agar an extraordinary pit can be seen under each colony. For many years, microbiologists discovered little more than this, other than to realize that $E$. corrodens was neither a true aerobe nor a true anaerobe but a "microaerophilic" bug that prefers a low level of oxygen. They dismissed the organism as a mere curiosity.

Over the last decade, however, modest improvements in culture technique have led to its recognition as the culprit in a wide range of infections. E.corrodens lives in the human mouth and upper respiratory tractwhich is why it comes to light when humans sink their teeth into other humans. It is a major cause of bone loss and tissue destruction in some types of periodontal disease. The many other diseases from which it has been isolated include meningitis, osteomyelitis, endocarditis, and septic arthritis, as well as infections of the liver and thyroid.

But how does the pitter attack such a wide variety of tissues? One of the first clues came a few years ago when Progulske-Fox and her Gainesville collabora-
B ER N A R D D I XON

tors found that the organism produced an endotoxin that destroys bone by promoting resorption. It also manufactures a slime that suppresses the immune response. When they began their molecular biological work, however, the Florida researchers decided to concentrate on the initial process through which the bacteria attach themselves to the mucosal surface-a process that might conceivably be thwarted as the basis of therapy or prophylactics.

As illustrated by microbes as diverse as influenza virus and Vibrio cholera, many mucosal pathogens initially adhere to the tissue by means of hemagglutinins, which are otherwise known for their ability to make erythrocytes clump together. Both the mucous membrane and red blood cells contain sialic acid which, when stripped away by a neuraminidase in human saliva or in the pathogen itself, leaves the underlying receptors exposed, allowing the invader to dock firmly onto the host cells.

$E$. corrodens seems to work in the same way. Some years ago it was found to agglutinate erythrocytes treated with neuraminidase. Likewise, the organism adheres to neuraminidase-treated human buccal epithelium cells and guinea-pig macrophages. The probable hemagglutinin of $E$. corrodens has since been isolated and characterized as a lectin-like substance.

In search of the hemagglutinin and other virulence determinants, Ann Progulske-Fox and her colleagues constructed a clone bank of $E$. corrodens chromosomal DNA in Escherichia coli. Of 22 clones expressing antigens from the parent organism they found not one but two that produced proteins that were capable of agglutinating erythrocytes. As reported in the current Journal of General Microbiology (139:651,1993), sequencing of the genes established that the two hemagglutinins, one of $17 \mathrm{kDa}$ and the other $31.5 \mathrm{kDa}$, were quite distinct and had no homology with any previously sequenced proteins. The Gainesville team should now be able to produce selective mutations in each of the hemagglutinins, and thereby determine the contribution each makes to the initiation and development of disease.

Meanwhile, they have looked into the likely function of two other $14 \mathrm{kDa}$ proteins that came from the clone which also produced the $31.5 \mathrm{kDa}$ hemagglutinin. Both turned out to have very strong homology with proteins formerly identified in other organisms as type 4 pilins. Analysis of ten further strains of E. corrodens showed that all had fragments homologous with one of the two pilin genes. Their role in disease now needs to be investigated too, but their occurrence in so many different isolates certainly indicates that they are likely to be significant for the survival and/or virulence of the organism. 